A infecção pelo trichomonas vaginalis e suas possíveis relações com a aquisição e transmissão do vírus HIV

CENTRO UNIVERSITÁRIO GERALDO DI BIASE - UGB

FUNDAÇÃO EDUCACIONAL ROSEMAR PIMENTEL

PRÓ-REITORIA DE ASSUNTOS ACADÊMICOS

INSTITUTO DE CIÊNCIAS DA SAÚDE

CURSO DE BIOMEDICINA

\title{
A INFECÇÃO PELO TRICHOMONAS VAGINALIS E SUAS POSSÍVEIS RELAÇÕES COM A AQUISIÇÃO E TRANSMISSÃO DO VÍRUS HIV
}

Rafael Euzébio Da Silva

Barra do Piraí - RJ

2018 


\title{
RESUMO
}

A tricomoníase é uma infecção que acomete homens e mulheres, provocada por um protozoário cosmopolita anaeróbio, o Trichomonas vaginalis, que atua no trato urogenital de ambos, sendo esta transmitida através da relação sexual, tornando-a a infecção sexualmente transmissível (IST) não viral mais comum no mundo, onde sua infecção é curável mais pode causar danos graves ao corpo humano. Apesar de ser pouco valorizada, ela tem uma grande relação na aquisição e transmissão do vírus da imunodeficiência humana (HIV), durante sua infecção sua patogenicidade influencia as respostas no sistema imunológico, onde também estão as células alvo do HIV, ocorrendo lise de células que acabam facilitando a exposição do vírus. O objetivo deste artigo é entender a relação do T. vaginalis com o HIV. Livros virtuais e impressos, e artigos em português, espanhol e inglês foram explorados para a formação da revisão bibliográfica presente neste trabalho. A tricomoníase muitas vezes é assintomática e com facilidade tem comunicação entre seus parceiros. São necessárias campanhas que orientem a população sobre essa IST.

Palavras-chaves: Trichomonas vaginalis, HIV, Tricomoníase, Infecção por protozoário, Parasitologia, IST's.

\begin{abstract}
Trichomoniasis is an infection that affects men and women, caused by an anaerobic cosmopolitan protozoan, the Trichomonas vaginalis, which acts in the urogenital system for both men and women, being transmitted through sexual intercourse, making it the not viral sexually transmitted infection (STI) most common in the world, which is curable but can cause several damage to the human body. Although little valued, it has a great relation in acquiring and transmission of human immunodeficiency virus (HIV), and during the infection its pathogenicity influences responses in the immune system, where are the cells affected by HIV, occurring the infection of cells that end up facilitating the exposure of the virus. The purpose of this article is to understand the relationship between T. vaginalis and HIV. Virtual and printed books, and articles in Portuguese, Spanish and English were explored to shape the present bibliographic review. Trichomoniasis is often asymptomatic and easily transmitted between its partners. Campaigns are needed to guide the population about this STI.
\end{abstract}


A infecção pelo trichomonas vaginalis e suas possíveis relações com a aquisição e transmissão do vírus HIV

Keyword: Trichomonas vaginalis, HIV, Trichomoniasis, Protozoan infection, Parasitology, STIs 


\section{INTRODUÇÃO}

A tricomoníase é a infecção sexualmente transmissível não viral mais comum no mundo, com incidência de 276 milhões de novos casos por ano e uma prevalência de 187 milhões de indivíduos infectados entre 15 e 49 anos, conforme relato da (OMS) Organização Mundial de Saúde (WHO, 2012). Seu agente etiológico, Trichomonas vaginalis, foi descrito em 1834, por Donné na França, em uma mulher com vaginite, ele é um protozoário cosmopolita anaeróbio que exibe uma forma piriforme ou arredondada, provido de grande mobilidade devido aos seus quatro pares de flagelos e uma membrana ondulante anterolateral. Mais de 100 espécies do gênero Trichomonas já foram descritas, porem somente três delas foram isoladas no homem: o T. tenax na cavidade oral, T. hominis no tubo digestivo e o T. vaginalis, sendo que somente ele foi prescrito uma patologia. (PARASITOLOGIA HUMANA., 2010)

A infecção ocorre no trato urogenital feminino e masculino e o ser humano é o único hospedeiro natural do parasita (MARITZ et al., 2014). O T. vaginalis apresenta apenas o estágio de trofozoíto, embora, sob condições estressantes, tenham sido descritos pseudocistos ou formas endoflagelares (PEREIRA-NEVES et al., 2003). O papel dessas formas resistentes no ciclo de vida das trichomonas ainda não é compreendido. Além de suas características únicas, T. vaginalis apresenta hidrogenossomos ao invés de mitocôndrias, organelas que estão envolvidas na adaptação do metabolismo ao ambiente de infecção hostil, incluindo vias específicas de morte celular (CHOSE, et al., 2003; BENCHIMOL, 2009).

O patógeno T. vaginalis é transmitido por intercurso sexual e as evidências que corroboram para a classificação da tricomoníase como IST são: (1) alta frequência de infecção na uretra e/ou próstata de parceiros masculinos de mulheres infectadas; (2) a prevalência de infecção é maior entre mulheres sexualmente ativas quando comparadas às mulheres virgens ou pós-menopausadas; e (3) os flagelados morrem fora do corpo humano, a menos que sejam protegidos da dessecação (PETRIN et al., 1998). Estudos que encontraram o T. vaginalis entre crianças pequenas contribuem para manter um alto índice de suspeita de abuso sexual (HAMMERSCHLAG \& GUILLEN, 2010; READING et al., 2014). Embora considerada rara, a transmissão não sexual por fômites e, possivelmente, por água já foram descritas (CRUCITTI et al., 2011). O patógeno também foi isolado do trato respiratório de lactentes e adultos (CARTER \& WHITHAUS, 2008; DUBOUCHER et al., 2003; LETERRIER et al., 2012). Indubitavelmente, ao produzir uma infecção incômoda, o T. vaginalis deve ser considerado um patógeno clínico, e não um organismo comensal. 
A infecção é curável, mas pode causar graves consequências para a saúde das mulheres como o câncer do colo do útero, a infertilidade, resultados adversos da gravidez levando à ruptura prematura das membranas placentárias, lactentes com baixo peso ao nascer e sua associação com o HIV (Imunodeficiência Humana Vírus) (FICHOROVA et al., 2009)

Certamente, um aspecto notável na infecção por T. vaginalis é sua associação positiva com a transmissão e a aquisição do HIV. As evidências que corroboram essa preocupação são substanciais, embora ainda pouco valorizadas (KISSINGER \& ADAMSKI, 2013). Estudos mostraram que a tricomoníase está associada a um aumento de até 2,7 vezes no risco de aquisição do HIV (POOLE \& MCCLELLAND, 2013). Esses dados são especialmente significativos, levando-se em conta a alta prevalência de tricomoníase na população geral e, em particular, nos grupos de risco (LEHKER \& ALDERETE, 2000). Algumas abordagens (por exemplo, modelagem matemática) foram desenvolvidas para estimar o número de infecções por HIV transmitidas atribuíveis a $T$. vaginalis, e a alta eficácia desses métodos está intimamente relacionada com a necessidade de melhorar o diagnóstico do parasita (QUINLIVAN et al., 2012). Desta forma o controle do T. vaginalis, através da prevenção, diagnóstico e tratamento, pode ter um impacto fundamental na prevenção da aquisição e transmissão do HIV. Portanto, o objetivo deste trabalho é entender como o T. vaginalis pode influenciar na aquisição e transmissão do vírus HIV, mostrando ainda, as principais formas de prevenção, tratamento e diagnóstico deste protozoário.

\section{METODOLOGIA}

Este artigo é uma pesquisa bibliográfica de abordagem qualitativa, revisando e explorando artigos científicos e livros impressos e virtuais, analisando a relação do $T$. vaginalis com as infecções pelo HIV, mostrando como o patógeno está relacionado ao risco 8 vezes maior por suas infecções, onde também será abordado: diagnóstico e prevenção do parasito e como amenizar sua relação com o HIV.

As fontes usadas foram Pubmed, Scielo, Portal Periódicos Capes e livros atualizados. Artigos foram versados, dando base e direção ao artigo presente, para sua descrição no ano de 2018, e também sendo foco para as palavras chaves T. vaginalis, HIV e IST's, os que não continham informações que enriquecessem este artigo foram descartados. 


\section{DESENVOLVIMENTO}

\subsection{Morfologia}

As infecções sexualmente transmissíveis (IST's) constituem um grupo de endemias de múltiplas causas que abrangem doenças venéreas inveteradas e um grande número de entidades clinicas e síndromes que tem como traço habitual a transmissão durante o intercurso sexual. Elas tornam-se importante devido ao alto risco de disseminação, provocando na maioria das vezes danos à saúde do indivíduo acometido. As consequências podem ser desde distúrbios emocionais, Doença Inflamatória Pélvica (DIP), infertilidade, lesões fetais, até câncer, além de facilitar a transmissão do vírus HIV (MORTOZA JUNIOR,2000).

$\mathrm{Na}$ luz de vários órgãos cavitários do homem e da mulher encontram-se muitos flagelados parasitos, na vagina da mulher, assim como na próstata e uretra do homem encontramos um flagelado denominado Trichomonas vaginalis. Três espécies dessas (T. vaginalis, T. tenax e T. hominis) pertencem a família Tricomonadidae, caracterizada por apresentarem de 3 a 6 flagelos, e um sistema de estruturas fibrilares, ligadas aos corpúsculos basais dos flagelos (blefaroplastos), uma das quais é descrita como axóstilo (REY, 2010).

De acordo com REY 2010, T. Vaginalis tem uma forma típica alongada e ovoide podendo chegar a 30 micrometros de comprimento e 12 de largura, não possui rigidez o que permite que ele emita pseudópodes. Quatro flagelos constituem sua parte anterior, caracterizando o canal periflagelar, sendo que este também possui um quinto flagelo voltado para trás que emerge fora desse canal, mantendo-se aderente em toda a extensão ao corpo celular, porém não chega até sua membrana ondulante e sim a extremidade posterior. Cada flagelo provem de um blefaroplasto, estes são feixes de estrutura fibrilar com distancias maiores ou menores no interior do citoplasma, são estes: axóstilo, tem forma de fita, uma justaposição de microtúbulos, com extensão no corpo celular e mantendo uma saliência no polo exterior; costa, próxima ao flagelo recorrente, nele encontramos uma faixa que parte do mesmo blefaroplasto; corpo parabasal, sendo uma mais alongada que a outra, são estas um conjunto de fibras e o aparelho de Golgi com suas vesículas e membranas paralelas.

Os Trichomonas são tipicamente descritos como células apresentando as formas trofozoíto e pseudocistos, a formação de pseudocistos refere-se à morfologia, transformação de Trichomonas em formas compactas sem uma verdadeira parede de cisto. Pseudocistos foram descritas em certos Trichomonas que residem em tratos gastrintestinais e presumivelmente 
representam uma resposta ao estresse ambiental. As formas de trofozoíto destes organismos, que são polares e flagelados, tornam-se arredondadas e desprovido de flagelos externos na formação de pseudocistos. O flagelo pode ser visto por residir dentro do citoplasma do pseudocisto (PEREIRA-NEVES et al.,2003).

\subsection{Patogênese}

Lehk \& Alderete (2000) relataram que varia de 3-28 dias o tempo de incubação do protozoário, e que um terço das pacientes assintomáticas se tornam sintomáticas no período de seis meses. Um passo essencial para esta patogênese são as células epiteliais do trato urogenital, local onde ocorre a aderência do parasita, pois o T. vaginalis infecta principalmente o epitélio escamoso do trato genital (CUDMORE et al.,2004).

Em 2005 Costa et al., notou que para se aderir às células epiteliais um processo complexo de cinco proteínas de superfícies denominadas adesinas foram encontradas, sendo estas (AP120, AP56, AP51, AP33 E AP23). Quatro destas adesinas possuem homologia com enzimas metabólicas porem a Ap23 ainda não foi identificada. Estas podem atuar como enzimas metabólicas nos hidrogenossomos e citoplasma e também como adesinas de superfície no parasito, como receptores de hemoglobina e heme, estas também participam de mecanismos de mimetismo molecular envolvidos na evasão imune, porem sabe-se que este último caso a AP120 não atua (ALDERETE et al., 2000).

Mendonza-Lopéz et al., 2000 descreveu também o lipofosfoglicano (LPG) de superfície, os receptores de matriz extracelular e as cisteínas proteinases (CPs), localizadas na superfície do parasita elas participam da citoaderência. CPs dependentes do ferro degradam o fator C3 da cascata de complemento, dirigem também um inibidor de proteases solúvel produzido por leucócitos (SLPI). Nos processos contato-independentes o parasito secreta moléculas como TvF (cell-free T. vaginalis culture fator) e a CDF (cell-detachining fator) estas atuam nos danos celulares. Já as CPs, TvCP65 e TvCP39, degradam colágeno IV, proteínas do meio vaginal e fibronectina, sendo estas as formadoras da matriz extracelular, degradam também as imunoglobulinas IgG, IgM, e IgA, no período menstrual. O TvCP30 induz a apoptose de células epiteliais, leucócitos T, macrófagos e células dentriticas.

$\mathrm{O}$ pH e os hormônios desempenham papeis na infecção que podem explicar o motivo dos sintomas aparecerem de forma mais rigorosa no período imediatamente após a menstruação. Durante este período, o pH vaginal aumenta, assim como a quantidade de ferro 
facilitando a fixação do parasita ao epitélio escamoso do trato vaginal. Além disso, o ferro é um fator essencial na regulação dos genes do parasita (PETRIN.,1998).

Um nível vaginal de $\mathrm{pH} \geq 4,6$ foi identificado como um fator de risco para tricomoníase. Brotman et al. [40] revelaram que 90\% das mulheres com tricomoníase têm um nível de pH> 4,5, que é um critério para o diagnóstico de vaginose bacteriana [41], infecção por T. vaginalis ou ambos. O bacilo de Doderlein é um dos componentes da flora vaginal responsável pela conversão do glicogênio em ácido láctico, que mantém uma acidez vaginal de aproximadamente 3,8 a 4,2 e impede o desenvolvimento de microrganismos patogênicos. Sabese que alterações no $\mathrm{pH}$ são responsáveis pela vaginose bacteriana (BV); no entanto, um pH alcalino acima de 4,5 está associado à presença de Trichomonas (O’HANLON et al., 2013).

\subsection{Sintomas}

A Tricomoníase varia de forma assintomática ao estado agudo, nas mulheres os sintomas não aparecem quando o pH e flora vaginal não estão alterados, $20 \%$ dos casos sintomáticos apresentam corrimento. Além disso, os sintomas são mais frequentes em mulheres grávidas e entre as mulheres que fazem uso de anticoncepcionais oral, devido ao aumento do pH vaginal que favorece a multiplicação do protozoário (PETRIN et al., 1998).

Os principais sintomas são vaginite, corrimento vaginal fluido abundante na cor amarelo-esverdeado bolhoso, de odor fétido, muito frequente no período pós-menstrual. No processo infeccioso notamos prurido ou irritação vulvovaginal, e dores no baixo ventre, a mulher ainda apresenta dificuldades para relação sexual, incômodos genitais externos e dores ao urinar (PARASITOLOGIA HUMANA., 2010). O Colpitis macularis, que conhecemos como cérvice com aspecto de morango, que é observado em 5\% das mulheres sintomáticas é um sinal especifico da tricomoníase (LEHKER; ALDERETE., 2000).

No homem quase a totalidade de casos é assintomática, porem em alguns notamos um quadro típico de uretrite gonocócica, fisgadas na uretra, e podemos também notar prostatite, vesiculite e epididimite, estas levando a oligospermia e até mesmo esterilidade (RIGO et $a l ., 2017)$. No período diurno, antes da passagem da urina nota-se um corrimento claro, viscoso e pouco abundante, com desconforto ao urinar e as vezes hiperemia do meato uretral, o parasito desenvolve-se no trato urogenital do homem em que o glicogênio é farto, nos assintomáticos o parasito localiza-se na uretra e as vezes migra para a próstata (PARASITOLOGIA HUMANA.,2010). 


\subsection{Diagnóstico e tratamento}

O diagnóstico da tricomoníase é bastante confuso, pois $75 \%$ dos homens e $50 \%$ das mulheres são assintomáticas. O diagnóstico não pode ter como base somente a apresentação clínica, visto que os sinais clássicos da tricomoníase como a cérvice de morango ou Colpitis macularis, é encontrado em apenas $2 \%$ e o corrimento espumoso são observados em $20 \%$ das mulheres infectadas, portanto, os exames laboratoriais são fundamentais para seu diagnóstico (NEVES., 2005).

A demonstração do parasito é fundamental para um diagnóstico fidedigno. $\mathrm{O}$ exame direto a fresco, facilita a visualização do protozoário flagelado móvel. A técnica consiste em coletar a secreção vaginal com uma pipeta grossa após colocar o especulo, esta secreção deve ser fixada em uma lâmina após ser diluída com soro fisiológico e coberta com uma lamínula, para ser observada ao microscópio em busca de trofozoítas se movimentando (PARASITOLOGIA HUMANA., 2010).

Alguns autores não indicam esta técnica por considerarem, uma técnica de baixa sensibilidade devido à perda de mobilidade do protozoário, quando retirado do corpo humano, apesar de seu baixo custo (PETRIN et al., 1998).

Já a cultura de secreção é indicada em casos suspeitos quando o exame direto a fresco é repetidamente negativo. É de simples interpretação e leva poucos dias para a identificação do parasito. Se o agente for encontrado em uma citologia oncótica de rotina, será preciso tratar. Uma opção de diagnóstico é a reação em cadeia da polimerase que apresenta percentuais mais elevados comparados a outros métodos diagnósticos (PETRIN et al.,1998, LEHKER; ALDERETE, 2000).

O tratamento indicado utiliza fármacos como metronidazol, tinidazol, ornidazol, nimorazol, carnidazol, secnidazol e flunidazol (PETRIN et al., 1998, NEVES, 2005, MAVEDZENGE et al., 2010).

No tratamento padrão utiliza-se $250 \mathrm{mg}$ de metronidazol, via oral, 3 vezes ao dia num período de sete dias, ou uma única dose de $2 \mathrm{~g}$. O parceiro da paciente tem que fazer o mesmo tratamento, apresentando sintoma ou não, para prevenção da reinfecção. O metronidazol tem altas taxas de cura, quando feito de forma adequada. $\mathrm{O}$ fracasso no tratamento geralmente acontece em recusa ou reinfecção pelo parasita (PETRIN et al., 1998).

Em 1960 o metronidazol foi aprovado para tratamento da tricomoníase, sua taxa percentual de cura chega a quase $100 \%$, no tratamento sistêmico, costuma ser prescrito em doses múltiplas ou únicas via oral ou intravenosa. Cremes e óvulos podem ser indicados no 
tratamento para mulheres, mais não são de grande eficácia comparado aos outros meios, já para homens não existe tratamento tópico (CUDMORE et al.,2004).

O metronidazol atua dentro da célula, penetrando através de difusão e é ativado no hidrogenossomos do T. vaginalis, desta forma ele altera constituição do DNA e das proteínas de membrana (TRACY, 1996).

\subsection{Prevenção}

A tricomoníase tem como forma de contagio a relação sexual, portanto o controle da mesma é constituído por medidas preventivas que são tomadas no combate de outras DST's (MACIEL; TASCAS; DE CARLI, 2004).

Recomendam-se mecanismos de prevenção como a pratica do sexo seguro, juntamente com aconselhamentos que ajudem a população a fazer as escolhas sexuais de forma mais adequada para reduzir a contaminação por agentes infecciosos, uso do preservativo, privação de contato sexuais com pessoas infectadas, limitação das complicações patológicas mediante tratamento imediato e eficaz, tanto para casos assintomáticos como sintomático, independente da tricomoníase ser diagnosticada em apenas um dos membros, ambos têm que fazer o tratamento (PARASITOLOGIA HUMANA., 2010).

\subsection{Tricomoníase e HIV}

O Trichomonas vaginalis é a infecção sexualmente transmissível mais prevalente no mundo, sendo esta, curável. Nos Estados Unidos uma pesquisa realizada em 2012, feita com a população mostrou a prevalência global de 3,1\% entre mulheres de 14 a 49 anos de idade. Outro estudo mostrou que a prevalência é 5 vezes maior entre mulheres do que entre homens. A tricomoníase é também frequentemente diagnosticada em pessoas infectadas com o Vírus Imunodeficiência Humana (HIV). (BACHAMANN et al., 2012).

Em 1981 a síndrome da imunodeficiência adquirida conhecida como AIDS marcou a história da humanidade. A epidemia da infecção pelo HIV (vírus da imunodeficiência humana) representa fenômeno global, de ocorrência nas diferentes partes do mundo, a AIDS destaca-se entre as enfermidades infecciosas emergentes pela sua grande magnitude e seus danos causados a saúde da população (BRITO et al., 2000).

AIDS é uma doença causada por um retrovírus, caracterizada por profunda imunossupressão que resulta em infecções oportunistas. Esse retrovírus com genoma RNA, faz 
parte da família Retroviridae e subfamília Lentivirinae. Os mecanismos de transmissão do vírus HIV incluem a forma sexual, transfusão sanguínea e também com acidentes de trabalho quando o perfuro-cortante foi utilizado em pacientes soropositivos, além da transmissão vertical quando a mãe passa o vírus para o filho no período de gestação, aleitamento ou parto (OLIVEIRA et al.,2006).

A doença causada pela infecção do HIV é caracterizada por supressão profunda da imunidade mediada por linfócitos TCD4 positivos (linfócitos TCD+). O principal alvo do vírus é o linfócito T auxiliar (helper), o HIV fixa-se a um marcador especial da célula T auxiliar denominado antígeno CD4. O vírus destrói a célula $\mathrm{T}$ auxiliar à medida que ele se prolifera (BARROS \& SCHNEIDER., 2012).

O HIV entra na célula através do complexo de duas proteínas virais, gp120 e gp41 localizadas no envelope viral, a glicoproteína gp120 tem grande atração pelas células CD4+, já a gp41 medeia a função do envelope viral com a membrana plasmática da célula o que permite que as proteínas virais associadas ao vírus e seu genoma entrem para o citoplasma (JANEWAY; TRAVERS., 1997).

Estudos realizados constataram que a infecção por T. vaginalis e o HIV possui relação bidirecional, onde a infecção por T. vaginalis favorece o HIV e esse, por vez, pode aumentar a tricomoníase (WANG et al., 2001).

O T. vaginalis ao infectar, provoca uma agressiva resposta imune celular local com inflamação na uretra do homem e do epitélio vaginal e exocérvice em mulheres, essa reposta é composta por um grande infiltrado de leucócitos, incluindo células alvo do HIV como TCD4+ e macrófagos, aos quais o HIV pode se ligar (PARASITOLOGIA HUMANA., 2010).

Com frequência o T. vaginalis provoca pontos hemorrágicos na mucosa, o que facilita o acesso direto do virus a corrente sanguínea, com isso os HIV-negativos tem um aumento na porta de entrada, e os HIV-positivos similarmente, com os pontos hemorrágicos e a inflamação tem um aumento nos níveis de vírus nos fluidos corporais e o número de linfócitos e macrófagos infectados pelo HIV encontrados na região genital. (FICHOROVA et al., 2009).

O processo inflamatório da mucosa vaginal induzido pelo Trichomonas vaginalis e a redução dos lactobacilos também facilitam a transmissão e infecção pelo HIV, além de propiciarem o local para aumento da replicação do vírus, facilitando a penetração na mucosa (OLIVEIRA et al.,2008).

Gunethner et al., em 2005 relatou que o T. vaginalis é favorecido em sua transmissão por ter a capacidade de degradar a secreção leucocitária inibidora da protease, sendo esta, um 
produto capaz de bloquear a invasão do vírus a célula, e que também pode ativar essas células imunes, estimulando o aumento a replicação do vírus devido ao aumento da produção de citocina TNF $\square \square$ na presença do parasito. Isso resulta no número de vírus livres e ligados aos leucócitos ampliando a porta de saída do HIV, desse modo, a probabilidade de transmissão e exposição é oito vezes maior no parceiro sexual não-infectado.

A infecção por T. vaginalis também foi associada a contaminação pelo vírus HIV. Um estudo prospectivo de 3297 casais africanos constatou que a infecção por T. vaginalis é um fator de risco para a aquisição do HIV; a infecção por T. vaginalis da parceira feminina foi associada ao aumento da probabilidade de adquirir HIV durante o sexo (HUGHES et al., 2012). Outro estudo prospectivo de 4948 mulheres sexualmente ativas no Zimbábue e na África do Sul descobriu que as mulheres infectadas por $T$. vaginalis tinham maior probabilidade de teste positivo para o HIV na visita seguinte, e de forma semelhante, mulheres infectadas pelo HIV tinham maior probabilidade de testar positivo para $T$. vaginalis na visita seguinte (MAVEDZENGE et al., 2010). A análise multivariada de dados de um estudo caso-controle conduzido entre 218 mulheres com infecção pelo HIV e 419 controles na Uganda e Zimbábue mostrou uma associação significativa entre receber um diagnóstico de infecção por T. vaginalis e subsequentemente testar positivo para infecção por HIV na visita seguinte (VAN DER POL et al., 2008). Em um estudo prospectivo de 1335 mulheres profissionais do sexo no Quênia, a infecção por T. vaginalis aumentou o risco de aquisição do HIV na análise multivariada (MCCLELLAND et al., 2007).

Um modelo matemático baseado em dados de pacientes infectados pelo HIV na Carolina do Norte previu que ocorreria 0,062 eventos de transmissão do HIV por 100 mulheres infectadas pelo HIV na ausência de infecção por T. vaginalis, e 0,076 eventos de transmissão do HIV ocorrerão se o T. vaginalis for prevalente em $22 \%$ das mulheres infectadas pelo HIV; no segundo cenário, mais de um quinto (23\%) dos eventos de transmissão do HIV de mulheres infectadas pelo HIV são atribuíveis à infecção por T. vaginalis (QUINLIVAN et al., 2012). Além disso, resultados de Chesson et al. (2004) mostram que aproximadamente 6,2\% de todas as infecções por HIV-1 entre mulheres dos EUA podem ser resultado da infecção por $T$. vaginalis. Já na África, a prevalência de HIV em mulheres infectadas por T. vaginalis é de 35,8\% (SALAWU \& CHELSEA, 2016).

Davis et al., (2016), mostraram uma alta taxa de infecção por T. vaginalis entre mulheres de uma comunidade sob supervisão, particularmente entre as mulheres HIV-positivas. Mais de um terço das mulheres HIV positivas foram infectadas com $T$. vaginalis, em oposição a 
aproximadamente um quinto das mulheres HIV-negativas. Esses e outros trabalhos tem mostrado que a co-infecção HIV e T. vaginalis afetam desproporcionalmente mulheres negras e classe socioeconômica baixa. Apesar do número crescente de pesquisas demonstrando sua importância, o T. vaginalis continua a ser amplamente ignorado no discurso da saúde pública, talvez por causa da demografia dos indivíduos mais afetados por esse patógeno. O rastreamento direcionado entre as populações de alto risco mais afetadas por essa infecção, como mulheres negras, grávidas ou de classe social baixa e seus parceiros, pode melhorar muito o controle da T. vaginalis e transmissão da infecção pelo HIV.

\section{CONSIDERAÇÕES FINAIS}

A infecção por Trichomonas vaginalis é altamente prevalente, muitas vezes assintomática e facilmente comunicável entre parceiros sexuais. A infecção está associada a riscos significativamente maiores de aquisição e transmissão do HIV, complicações na gravidez, incluindo parto prematuro.

O diagnóstico laboratorial é essencial nas manifestações clinicas, onde a tricomoníase acaba sendo confundida com outras DST's. Geralmente, a tricomoníase pode ser curada com terapia de dose única de um antibiótico nitroimidazol apropriado (por exemplo, metronidazol ou tinidazol).

Mais estudos são necessários para identificar estratégias efetivas de intervenção para reduzir as disparidades de saúde associadas a diferenças raciais / étnicas e relacionadas à idade.

Por fim, são necessárias políticas e campanhas que orientem as pessoas em relação a essa DST, promovendo a educação sexual por meio de palestras educativas, mensagens em TV's, no intuito de diminuir a tricomoníase e com isso também diminuir a relação de doença com a transmissão do HIV.

\section{Referências}

ANDERSON, Brenna L. et al. Effect of trichomoniasis therapy on genital HIV viral burden among African women. Sexually transmitted diseases, v.39, n.8, p.638, 2012.

KUMAR et al. Robbins \& Cotran Patologia - Bases Patológicas das Doenças. Editora Elsevier, 2010.

BENCHIMOL M. et al. Hydrogenosomes under microscopy. Tissue Cell, v.41, n.3, p.151168, 2009. 
BRITO, Ana Maria de et al. AIDS e infecção pelo HIV no Brasil: uma epidemia multifacetada. Rev. Soc. Bras. Med. Trop., Uberaba, v.34, n.2, p.207-217, abr. 2001.

BROTMAN, Rebecca M. et al. Association between Trichomonas vaginalis and vaginal bacterial community composition among reproductive-age women. Sexually transmitted diseases, v.39, n.10, 2012.

CARTER, J. Elliot; WHITHAUS, Kenneth C. Neonatal respiratory tract involvement by Trichomonas vaginalis: a case report and review of the literature. The American journal of tropical medicine and hygiene, v.78, n.1, p.17-19, 2008.

CHESSON, Harrell W. et al. The estimated direct medical cost of sexually transmitted diseases among American youth, 2000. Perspectives on sexual and reproductive health, v.36, n.1, 2004.

CHOSE O, Sarde et al. Cell death in protists without mitochondria. Annals of the New York Academy of Sciences, v.1010, p.121-125, dez. 2003.

DA COSTA, Rodrigo Furtado Madeiro et al. Trichomonas vaginalis perturbs the junctional complex in epithelial cells. Cell research, v.15, n.9, p.704-716, 2005.

CRUCITTI T, Jespers et al. Non-Sexual Transmission of Trichomonas vaginalis in Adolescent Girls Attending School in Ndola, Zambia. PLoS ONE, v.6, n.1, 2011.

CUDMORE, Sarah L. et al. Treatment of infections caused by metronidazole-resistant Trichomonas vaginalis. Clinical microbiology reviews, v.17, n.4, p.783-93, 2005.

DAVIS, Alissa et al. Trichomonas vaginalis and Human Immunodeficiency Virus Coinfection Among Women Under Community Supervision: A Call for Expanded T. vaginalis Screening. Sexually transmitted diseases, v.43, n.10, p.617-22, 2016.

DUBOUCHER, Christophe et al. Pulmonary coinfection by Trichomonas vaginalis and Pneumocystis sp. as a novel manifestation of AIDS. Human pathology, v.34, n.5, p.508-511, 2003.

FICHOROVA, Raina N. et al. Endobiont Viruses Sensed by the Human Host - Beyond Conventional Antiparasitic Therapy. PLoS ONE, v.7, n.11, 2012.

FICHOROVA, Raina N. Impact of T. vaginalis infection on innate immune responses and reproductive outcome. Journal of reproductive immunology, v.83, n.1-2, p.185-189, 2009.

OTAROLA U., Claudia et al. Frecuencia de tricomonas vaginalis detectadas mediante papanicolaou en cuatro servicios de salud, 1997-2002. Rev. chil. obstet. ginecol. Santiago, v.70, n.1, p.3-7, 2005.

GUENTHNER, Patricia C. et al. Trichomonas vaginalis-induced epithelial monolayer disruption and human immunodeficiency virus type 1 (HIV-1) replication: implications for the sexual transmission of HIV-1. Infection and immunity, v.73, n.7, p.4155-60, 2005.

HAMMERSCHLAG, Margaret R.; GUILLÉN, Christina D. Medical and legal implications of testing for sexually transmitted infections in children. Clinical microbiology reviews, v.23, n.3, p.493-506, 2010. 
HUGHES, James P. et al. Determinants of per-coital-act HIV-1 infectivity among African HIV-1-serodiscordant couples. The Journal of infectious diseases, v.205, n.3, p.358-65, 2012.

JANEWAY, C. A.; TRAVERS, P.; WALPORT, M.; CAPRA, J. D. Imunobiologia: O Sistema Imunológico na Saúde e na Doença. Porto Alegre: Artmed, 2000.

KISSINGER, Patricia; ADAMSKI, Alys. Trichomoniasis and HIV interactions: a review. Sexually transmitted infections, v.89, n.6, p.426-33, 2013.

KISSINGER, Patricia et al. Trichomonas vaginalis treatment reduces vaginal HIV-1 shedding. Sexually transmitted diseases, v.36, n.1, p.11-6, 2009.

BACHMANN, Laura H. et al. Trichomonas vaginalis genital infections: progress and challenges. Clinical Infectious Diseases, v.53, n.3, p.S160-S172, 2011.

LEHKER, Michael W.; ALDERETE, John F. Biology of trichomonosis. Current opinion in infectious diseases, v.13, n.1, p.37-45, 2000.

LETERRIER, Marion et al. Trichomonads in pleural effusion: case report, literature review and utility of PCR for species identification. Microbiologica-Quarterly Journal of Microbiological Sciences, v.35, n.1, p.83, 2012.

MACIEL, Gisele de Paiva; TASCA, Tiana; DE CARLI, Geraldo Attilio. Clinical aspects, pathogenesis and diagnostic of Trichomonas vaginalis. Jornal Brasileiro de Patologia e Medicina Laboratorial, v.40, n.3, p.152-160, 2004.

MARITZ, Julia M. et al. What is the importance of zoonotic trichomonads for human health? Trends in parasitology, v.30, n.7, p.333-341, 2014.

MAVEDZENGE, Sue Napierala et al. Epidemiological synergy of Trichomonas vaginalis and HIV in Zimbabwean and South African women. Sexually transmitted diseases, v.37, n.7, p.460-466, 2010.

LÓPEZ, Luciene Bottentuit et al. Strategies by which some pathogenic trichomonads integrate diverse signals in the decision-making process. Anais da Academia Brasileira de Ciências, v.72, n.2, p.173-186, 2000.

MORTOZA JUNIOR, G. Doenças sexualmente transmissíveis. In: Manual do TEGO. ed. Rio de Janeiro: Sociedade Brasileira de obstetrícia e ginecologia de Minas Gerais, 2000.

NEVES, D. P. et al. Parasitologia Humana. 11. Ed. São Paulo: Editora Atheneu, 2005.

NIBALI, Luigi; HENDERSON, Brian (Ed.). The human microbiota and chronic disease: Dysbiosis as a cause of human pathology. John Wiley \& Sons, 2016.

OLIVEIRA, Paula Matos et al. Vulvovaginites em mulheres infectadas pelo vírus da imunodeficiência humana. Revista Brasileira de Ginecologia e Obstetrícia, v.30, n.3, p.121126, 2008.

KISSINGER, Patricia; ADAMSKI, Alys. Trichomoniasis and HIV interactions: a review. Sexually transmitted infections, v.89, n.6, p.426-433, 2013. 
PAZ-BAILEY, Gabriela et al. Determinants of HIV type 1 shedding from genital ulcers among men in South Africa. Clinical infectious diseases, v.50, n.7, p.1060-1067, 2010.

PEREIRA-NEVES, Antonio; RIBEIRO, Karla Consort; BENCHIMOL, Marlene. Pseudocysts in trichomonads-new insights. Protist, v.154, n.3-4, p.313-329, 2003.

PETRIN, Dino et al. Clinical and microbiological aspects ofTrichomonas vaginalis. Clinical microbiology reviews, v.11, n.2, p.300-317, 1998.

POOLE, Danielle N.; MCCLELLAND, R. Scott. Global epidemiology of Trichomonas vaginalis. Sexually transmitted infections, v.89, n.6, p.418-422, 2013.

PRICE, Matthew A. et al. Addition of Treatment for Trichomoniasis to Syndromic Management of Urethritis in Malawi: A Randomized Clinical Trial. Sexually transmitted diseases, v.30, n.6, p.516-522, 2003.

QUINLIVAN, E. Byrd et al. Modeling the impact of Trichomonas vaginalis infection on HIV transmission in HIV-infected individuals in medical care. Sexually transmitted diseases, v.39, n.9, p.671, 2012.

MCCLELLAND, R. Scott et al. Infection with Trichomonas vaginalis increases the risk of HIV-1 acquisition. The Journal of infectious diseases, v.195, n.5, p.698-702, 2007.

READING, Richard et al. Gonorrhoea, chlamydia, syphilis and trichomonas in children under 13 years of age: national surveillance in the UK and Republic of Ireland. Archives of disease in childhood, v.99, n.8, p.712-716, 2014.

RIGO, Graziela Vargas et al. Diamine derivative anti-Trichomonas vaginalis and antiTritrichomonas foetus activities by effect on polyamine metabolism. Biomedicine \& pharmacotherapy, v.95, p.847-855, 2917.

TRACY, J. W.; WEBSTER, L. T. Drugs used in the chemoterapy of protozoal infections. In: GOODMAN, Louis Sanford et al. Goodman and Gilman's the pharmacological basis of therapeutics. New York: McGraw-Hill, 1996.

VAN DER POL, Barbara et al. Trichomonas vaginalis infection and human immunodeficiency virus acquisition in African women. The Journal of infectious diseases, v.197, n.4, p.548-554, 2008.

WANG, Chia C. et al. The effect of treatment of vaginal infections on shedding of human immunodeficiency virus type 1. The Journal of infectious diseases, v.183, n.7, p.1017-1022, 2001.

WORLD HEALTH ORGANIZATION et al. Prevalence and incidence of selected sexually transmitted infections, Chlamydia trachomatis, Neisseria gonorrhoeae, syphilis and Trichomonas vaginalis: methods and results used by WHO to generate 2005 estimates. World Health Organization, 2011. 